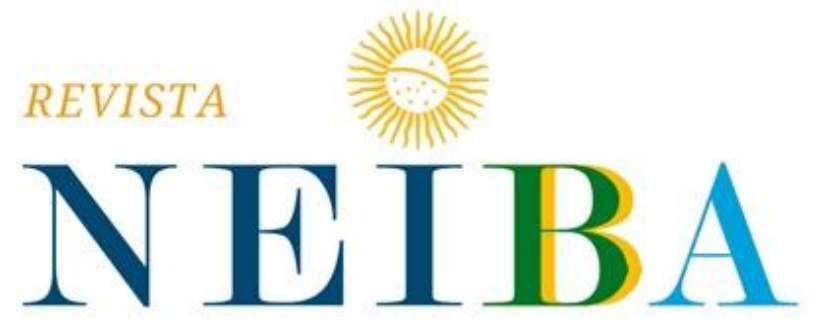

CADERNOS ARGENTINA-BRASIL
Volume 9, 2020, p. 01-21

DOI: $10.12957 /$ neiba.2020.50558 | e50558 I ISSN: 2317-3459

\title{
MÍDIA E POLÍTICA EXTERNA BRASILEIRA: UMA ABORDAGEM CRÍTICA
}

MEDIA AND BRAZILIAN FOREIGN POLICY: A CRITICAL APPROACH

\section{Eduardo da Nóbrega Monteiro ${ }^{1}$}

\section{Mônica Leite Lessa²}

${ }^{1}$ Universidade do Estado de Rio de Janeiro (UERJ), Rio de Janeiro, RJ, Brasil, eduardo.nobre.monteiro@gmail.com ORCID: https://orcid.org/0000-0001-9005-8270

${ }^{2}$ Universidade do Estado de Rio de Janeiro (UERJ), Rio de Janeiro, RJ, Brasil, monicaleitelessa@gmail.com ORCID: https://orcid.org/0000-0002-9332-2345

Recebido em: 01/01/2020 | Aceito em: 27/04/2020. 


\section{RESUMO}

Este artigo abordará a relação entre a mídia e a política externa brasileira em momentos de crise regional. Para tanto, as narrativas de liderança brasileira, construídas pela Mídia nacional- no caso, jornal o Globo - sobre a região da América do Sul serão retratadas em quatro momentos de crise diferentes, mas com dois países apenas: Bolívia e Venezuela. As crises são: (i) na tentativa de golpe de Estado na Venezuela, em 2002; (ii) durante a nacionalização dos hidrocarbonetos bolivianos, em 2006; (iii) a vinda do senador boliviano Roger Pinto, em 2013; e (iv) a suspensão da Venezuela no Mercosul, em 2016. O marco teórico deste artigo se pauta na Teoria Crítica e apresenta propostas para se analisar o papel da mídia na sociedade e sua relação com a política externa brasileira em momentos específicos.

Palavras-chave: Mídia; Política Externa Brasileira; Teoria Crítica.

\section{ABSTRACT}

This article will address the relation between the media and the Brazilian Foreign Politic in times of regional crisis. By doing so, the narratives of the Brazilian leadership, built by the national media - in this case, the newspaper O Globo - about the South American region will be portrayed in four different scenarios of crisis, but with only two countries: Bolivia and Venezuela. Those crises are: (i) the attempted coup in Venezuela in 2002; (ii) during the nationalization of the Bolivian hydrocarbons, in 2006; (iii) with the Bolivian senator Roger Pinto, in 2013; and (iv) the suspension of Venezuela in Mercosur, in 2016. The theoretical framework of this article is based on the Critical Theory and it presents pathways to analyze the role of the media in society and its relations with the Brazilian Foreign Policy.

Keywords: Media; Brazilian Foreign Policy; Critical Theory. 
1. COMUNICAÇÃO E RELAÇÕES INTERNACIONAIS: PANORAMA HISTÓRICOCONCEITUAL DA TEORIA CRÍTICA

A área de Comunicação muito se assemelha com a área de Relações Internacionais por algumas características que as unem. Ambas as áreas possuem múltiplas abordagens, teorias e epistemologias que as levam a ser não só interdisciplinares, mas também polissêmicas ou associativas (Martino, 2015). A interdisciplinaridade é marca da Comunicação ao agregar ferramentas metodológicas da ciência política e da linguagem, o que se aproxima fortemente da área de Relações Internacionais (RI) ainda mais em seu aspecto mais contemporâneo. As RI foram tradicionalmente ligadas às disciplinas do Direito, da Economia, da História e dos estudos relativos à diplomacia e segurança; com o decorrer dos debates e da virada sociolinguística, no entanto, a área tem se apoiado e estado mais aberta a novas percepções acerca dos acontecimentos internacionais.

Considera-se, também, fundamental o emprego das abordagens comunicativas para se compreender acontecimentos internacionais. França et al. $(2018$, p. 6) atestam que a "área de Comunicação e Política é bastante consolidada no campo científico da comunicação" e, também por isso, o campo das Relações Internacionais não pode deixar de se enxergar nesse meio comunicacional - seja na esfera local ou global ${ }^{3}$. Além disso, diversos autores já implementaram análise de discurso da imprensa e suas comunicações políticas, o que demonstra, mais uma vez, a necessidade do campo em se aprofundar no tema (Lattman-Weltman, 1994; Miguel, 1999, 2004; Lima, 2004a). Há, no entanto, alguns poucos autores da área das Relações Internacionais e da Ciência Política que já trabalharam sobre o tema (Casarões, 2012; Faria, 2008; Salomón, Pinheiro, 2013; Monteiro, 2007; Camargo, 2012; Lessa, Gavião, 2010).

A partir de Gilboa (1987; 2001), considera-se a premissa de que os Estados nacionais têm sido confrontados com a redução de seu poder de influenciar a informação veiculada. Em parte, devido à globalização e à política de governança global, como sustentam Held e McGrew (2001), em parte devido à projeção das mídias vinculadas aos conglomerados comunicacionais mundiais.

\footnotetext{
${ }^{3}$ Rousiley Maia, professora da UFMG, fez uma revisão de literatura internacional sobre o tema comunicação e política em Mídia e deliberação (França et al., 2018, p. 20)
} 
Tendo em vista essas constatações, percebeu-se um adensamento em um certo tipo de enfoque. Estudos com ênfase em Análise de Conteúdo, utilizando Laurence Bardin, e em Análise de Discurso, sustentados pelos estudos de Dominique Maingueneau, a área de RI muito se aproximou de algumas agendas de pesquisa da área de Comunicação, especialmente às ligadas ao texto ou ao intertexto. No entanto, há um ponto de contato onde RI e Comunicação se encontram que não tem sido explorado da maneira que se julga ser necessária; as contribuições da Teoria Crítica tanto para as RI quanto para a Comunicação podem ser vistas como uma possibilidade de pesquisa.

A partir de uma perspectiva histórica, algumas conexões podem ser encontradas para demonstrar essa relação direta entre as duas áreas; para tanto, Aristóteles e suas reflexões acerca do Homem Político e Social, e Deibert (1997), ao descrever a posse de informações, desde a Idade Média, nas mãos de poucos. Aristóteles (1967, p.1252a1253b) já comentava acerca da constituição da comunidade política - polis - a partir da comunicação e do fato de o homem ser um animal político que se comunica. Essa característica comunicacional é o diferencial dos seres humanos, uma vez que ela é feita para criar consensos sobre as regras que organizam o viver comum da cidade Atenas no caso. É claro que o papel comunicacional dos humanos para a conformação de uma sociedade organizada já demonstra uma ligação no século IV a.c., ainda que de maneira incipiente, já que a sociedade foi mudando. Alguns séculos depois, Deibert (1997) sustenta que o poder da Igreja Católica Romana na Idade Média estava diretamente relacionado à sua capacidade de ser a monopolizadora da informação e da comunicação. Naquela época, a comunicação era, basicamente, oral e a parte escrita era exclusiva da Igreja - além do Latim ser uma língua estudada pela própria instituição, o que gerava mais concentração. Com o advento da impressão e da queda do modelo feudal, a Reforma Protestante e o cientificismo humano iluminista tornaram-se forças dissidentes poderosas por possuírem a capacidade de espalhar a informação com intensidade incomum. Todo esse cenário trouxe mudanças no pensamento social europeu, que passou a questionar, em larga escala, a hierarquia e, consequentemente, a submissão provocada pelo monopólio da língua e da crença pela Igreja Católica. Criase a sociedade moderna com bases contratualistas e liberais, na qual a urbanização é 
recrudescida pela burguesia e pelo êxodo rural (Deibert, 1997).

A sociedade liberal-burguesa criada após as revoltas contra as monarquias foi cenário para que filósofos da época tentassem entender o fenômeno que se desenhava. Nesse sentido, Karl Marx e Friedrich Engels lançam o Manifesto do Partido Comunista com alguns anseios, entre eles, solicitar o caráter cientificista do socialismo - contrário ao que Marx e Engels chamaram de socialismo romântico - e despertar o espírito revolucionário a partir do novo cenário dos meios de comunicação (Brunkhorst, 2008). Nesse primeiro momento, o que seria a base da Teoria Crítica entende que os novos meios de comunicação são libertadores, a partir das reflexões de classe. Brunkhorst (2008, p. 300) alerta que "para Marx, Ernst Bloch, Adorno e Marcuse a tecnologia fica ao lado do 'extenuado e sobrecarregado, do "oprimido e degradado'”. Marx (2011b) já passa a entender de uma forma um pouco diferente o papel da expansão tecnológicacomunicacional quando analisa a ascensão de Luís Bonaparte. Houve utilização dos meios de comunicação da época para que fossem feitas propagandas, plebiscitos e manipulações de proclamação. Dessa forma,

\begin{abstract}
A partir da perspectiva do acontecimento histórico, o potencial para a liberdade e para a solidariedade, que se desenvolve com a disseminação ilimitada de meios sempre mais novos de comunicação, é acompanhada pela sombra de um não menos considerável potencial para a repressão e para a manipulação [...] a sensata descoberta do Dezoito de Brumário é a de que os novos meios de comunicação obviamente aceleram não apenas a solidariedade das massas exploradas, mas também aquela entre seus senhores. (Brunkhorst, 2008, p. 303-304)
\end{abstract}

Seguindo essa primeira linha de pensamento da escola da Teoria Crítica, Theodor Adorno escreve, em Educação pós-Auschwitz, sobre o papel libertador dos meios de comunicação. Brunkhorst (2008) descreve que Adorno tinha uma percepção de que a tecnologia mitigaria o "barbarismo" da vida do campo, o que se associa com um certo determinismo tecnológico. Na sequência, no entanto, Brunkhorst (2008, p. 304, sic) narra que "após a experiência de o rádio se tornar a 'garganta universal' do Führer" no fascismo, Adorno avança tese contrária a anterior ao dizer que a tendência do rádio é a de "transformar recomendações em atos diretivos de comandos". Ao se distanciar de Walter Benjamim e da teoria socialmente otimista do rádio de Brecht ${ }^{4}$, Adorno inaugura

\footnotetext{
${ }^{4}$ Cabe um contraponto sobre o otimismo de Brecht, como salienta Celso Frederico (2007, p. 223) ao dizer que "o rádio não criou nada de novo, apenas reproduziu procedimentos próprios dos meios anteriores. Cada novo meio de
} 
uma nova tendência do pensamento crítico que é o de enxergar os meios de comunicação dentro da chave sistêmica cultural. Os autores Horkheimer, Marcuse e Adorno perceberam que "a filosofia positiva da história - superada por Marx em face de suas experiências negativas, mas renovada ulteriormente no marxismo ortodoxo reverte-se em seu oposto: uma filosofia negativa da história" (Brunkhorst, 2008, p. 306)

Nessa linha, Adorno e Horkheimer (2012) já mudam sua perspectiva ao publicar a Dialética do Esclarecimento em 1947. Ao sustentarem o conceito de esclarecimento aplicado à indústria cultural, Adorno e Horkheimer (2012, p. 113) afirmam que "a cultura contemporânea confere a tudo um ar de semelhança" e que o "cinema, o rádio e as revistas constituem um sistema", no qual cada um é coerente para o conjunto. A redução da sociedade a um único sistema completo, resultado a partir da cultura de massas, a tornaria enrijecida e que essa unificação impossibilitaria de saber o que é proibido e o que não é, dando controle total à indústria cultural.

Quanto mais firmes se tornam as posições da indústria cultural, mais sumariamente ela pode proceder com as necessidades dos consumidores, produzindo-as, dirigindo-as, disciplinando-as e, inclusive suspendendo a diversão: nenhuma barreira se eleva contra o progresso cultural. (Adorno; Horkheimer, 2012, p. 135)

Essa sistematização do poder da indústria cultural e sua quase invisibilidade muito se assemelha à teoria foucoultiana de poder. Brunkhorst (2008) também lembra sobre a teoria feminista do sujeito e da forma como ela foi desenvolvida, dando segmento a Foucault e Althusser, a partir do trabalho de Judith Butler ${ }^{5}$. O poder se constituiria, seguindo Butler (1997), a partir do momento que o sujeito o exerceria sobre si e, por esse meio, obteria espaço para autonomia em sentido mais amplo. Adorno e Horkheimer (2012) se assemelham ao tratar da noção cíclica, mas entendem que a unilateralidade da manipulação causal é superada. Ainda que as massas tenham aspirações, elas apoiam firmemente a ideologia pela qual estão sendo dominadas ou subjugadas, o que Adorno (2009) sustenta como o paradoxo da autonomia ${ }^{6}$. Brunkhorst (2008), ao comentar sobre o paradoxo da autonomia de Adorno, salienta uma citação

comunicação parece condenado a representar o papel de vampiro que se alimenta das invenções anteriores". Frederico (2007) acredita que não havia otimismo ingênuo em Brecht.

${ }^{5}$ Quando Brunkhorst (2008) menciona Butler, ele comenta especificamente de Butler (1997), quando entende que o poder não só forma o sujeito, mas também condiciona seu desejo.

${ }^{6}$ Adorno (2009) retoma o conceito kantiano de liberdade e sustenta que não pode existir qualquer conceito de autonomia que não leve a consequências heteronômicas. 
que vale a pena ser transcrita para fechar esse argumento

os sujeitos são livres [...] na medida em que são conscientes de si mesmos e idênticos a si mesmos; e, novamente, não são livres em tal identidade na medida em que permanecem sob e perpetuam as limitações dessa identidade. Enquanto naturezas não idênticas e difusas, eles não são livres e, todavia, como tal, eles são livres, visto que suas agitações esmagadoras - pois a não identidade do sujeito consigo mesmo não é nada além disso - livramnos do caráter limitante da identidade (Adorno, 2009 apud Brunkhorst, 2008, p. 311)

Jürgen Habermas critica essa ideia massificadora de Adorno e Horkheimer (2012) e propõe outras visões. Habermas argumenta que a sociedade é totalmente definida pela comunicação entre os indivíduos e que a negação determinada - partindo de Hegel - é base para as contradições existentes na sociedade. Resumidamente, Habermas retoma o conceito de cultura de volta à sociedade e enxerga a arte, seja ela de massa ou não, com um caráter possivelmente antitradicionalista ou revolucionário por tratar de questõesque podem invocar sentimentos dessa magnitude. Ao repensar dessa forma, é possível perceber distinções no público e no privado, o que iria de encontro à tese defendida por Adorno e Horkheimer (2012) do poder invisível. Para Habermas (1988, p. 70, tradução minha) o "espaço de manobra" do Estado é "limitado, já que o sistema cultural é particularmente resistente ao controle administrativo: não existe produção administrativa de sentido". (Brunkhorst, 2008, p. 319-326)

Essa falsa sensação de liberdade e a perspectiva sistêmica da sociedade, faz com que se levantem questionamentos acerca de movimentos de inclusão ou de exclusão. Ainda que haja uma massificação da vontade dos indivíduos, a preocupação sobre o que é válido e o que não é está, também, no cerne da Teoria Crítica. Nesse cenário, pode-se perceber tanto para a área de comunicação - quando se pensa em julgamentos morais sobre condutas de governos - quanto para a área das RI, especificamente Linklater (1992) ao abordar o que os Estados incluem ou excluem. Há possibilidades de interação, seguindo a Teoria Crítica, quando se pensa em movimentos migratórios, acordos comerciais no âmbito internacional, meio ambiente e em ações esperadas em momentos de crise. Essa preocupação é característica dessa corrente teórica e se assemelha com trabalhos de correntes diferentes, como o pós-estruturalismo, o póscolonialismo e o feminismo.

A Teoria Crítica tem, como um dos propósitos principais, a emancipação por conta 
das relações desiguais de poder. O termo "emancipação" pode sugerir uma posição, em tese, privilegiada do autor, que poderia chancelar ou não o momento emancipatório, como um médico poderia liberar seu paciente. Essa problemática que vem desde Kant, Marx e Hegel foi interpretada pela Escola de Frankfurt, especialmente Habermas e Axel Honneth, como sendo uma distorção ou um problema patológico na comunicação, uma vez que essa era distorcida pela relação desigual de poder. Nesse caso, a emancipação está voltada para a remoção da distorção na comunicação, o que passa diretamente pelas relações de poder inter e intraestatais. (Shapcott, 2008)

É a partir dessa observação que esta dissertação se insere ao abordar a relação entre a Mídia ${ }^{7}$ e a Política Externa brasileira. Para isso, será utilizada a Teoria Crítica e autores que trabalhem de forma relativamente próximas às preocupações dessa corrente. Já existe uma literatura sobre Mídia e Política tanto no estrangeiro quanto no doméstico, no entanto há uma lacuna específica na área de Relações Internacionais em não trabalhar a temática das mídias. Nesse caso, especificamente, há pouquíssimos trabalhos que tentem aliar a Teoria Crítica para as Relações Internacionais e com a preocupação de analisar a relação entre a Mídia e a Política Externa. (Macmillan, 2004).

\section{A MÍDIA EM MOMENTOS DE CRISES DE POLÍTICA EXTERNA: \\ i. Os Quatro Casos}

Primeiramente, gostaria de salientar que escolhi as seguintes páginas do GLOBO, pois essas apresentaram não só o maior número de menções aos casos, mas também têm mais relevância ao trabalho: Primeira Página; Segunda Página; Opinião; Mundo; País; Economia. Além disso, há uma importância na primeira página do jornal, porque "pode informar sobre seus objetivos e sobre a maneira como cada diário se posiciona política, cultural e socialmente" e, também, "reflete as escolhas feitas pelos editores" (Medeiros, Ramalho e Massarani, 2010). Esse fato foi constatado nesta pesquisa, uma vez que as primeiras páginas eram indicativas de toda uma cobertura nas páginas subsequentes. A Segunda página era utilizada como se fosse um resumo das principais notícias do jornal, além de demonstrar pesquisas internas acerca de quais matérias

\footnotetext{
${ }^{7}$ Entendo mídia nos moldes de Lima (2004, p. 50): “A mídia, plural latino de médium, meio, será aqui entendida como o conjunto das instituições que utiliza tecnologias específicas para realizar a comunicação humana".
} 
chamaram mais a atenção do leitor de uma edição para a outra. A página de Opinião é especialmente importante, porque ela não só é espaço para outras opiniões - o que denotaria uma certa pluralidade -, mas também é espaço para a opinião do jornal. As demais páginas (Mundo, País e Economia) foram escolhidas por serem locus de debates internacionais e que envolvem economia.

A metodologia empregada foi a metodologia de análise de valência ${ }^{8}$. Os meses $^{9}$ escolhidos seguiram o padrão de terem sido no momento da conformação da ideia de crise para o jornal. A intenção foi a de qualificar as menções que tiveram destino ao executivo federal, representado pelo presidente do momento, bem como aos seus chanceleres e aos assessores internacionais. Nos casos de anos de eleição - em 2002 e em 2006 - optou-se por manter o padrão e tentar separar os candidatos tanto a reeleição quanto a eleição. Para isso, o método de valência visa analisar quais notícias são positivas (+1), neutras (0) ou negativas (-1) à imagem do executivo federal e, com isso, consubstanciou-se o gráfico 02 para demonstrar como foi a cobertura sobre esse aspecto, durante o tempo escolhido. A intenção é a de analisar o "espaço ocupado [e] a análise quantitativa da cobertura", o que permite "avaliar a valência, ou seja, a orientação positiva ou negativa da cobertura" (Aldé, Mendes e Figueiredo, 2007, p.155)

Durante a pesquisa, foi perceptível tal aumento nas menções aos países envolvidos nos meses escolhidos. No caso da Bolívia, por exemplo, em maio de 2006, o assunto foi importante durante o mês, perdeu importância durante a Copa do Mundo, voltou a ter importância com a aproximação das eleições de 2006, mas, depois, teve menções discretas ao final do ano. Cabe mencionar que pode haver duas ou mais menções na mesma notícia e que a essa análise focou nas notícias que trataram do acontecimento e que se posicionaram com relação às atitudes do executivo federal; não é, portanto, dissociativa o número de páginas com o número de menções ${ }^{10}$.

\footnotetext{
8 Tal metodologia vem sendo desenvolvida pelo DOXA-IESP e pelo Manchetômetro (disponível em: < http://www.manchetometro.com.br>). Para um debate acadêmico, cf.: Miguel $(2015 ;$ 2016) e Feres Junior (2016).

9 Empreguei $t=31$ dias para fins do gráfico 02.

${ }^{10}$ Há algumas menções na parte de "Carta dos Leitores" e, embora haja uma certa controvérsia com relação a esse uso, preferi não as considerar como parte das notícias do jornal. Além do mais, essa ressalva vale para o caso venezuelano
} 
Gráfico 1

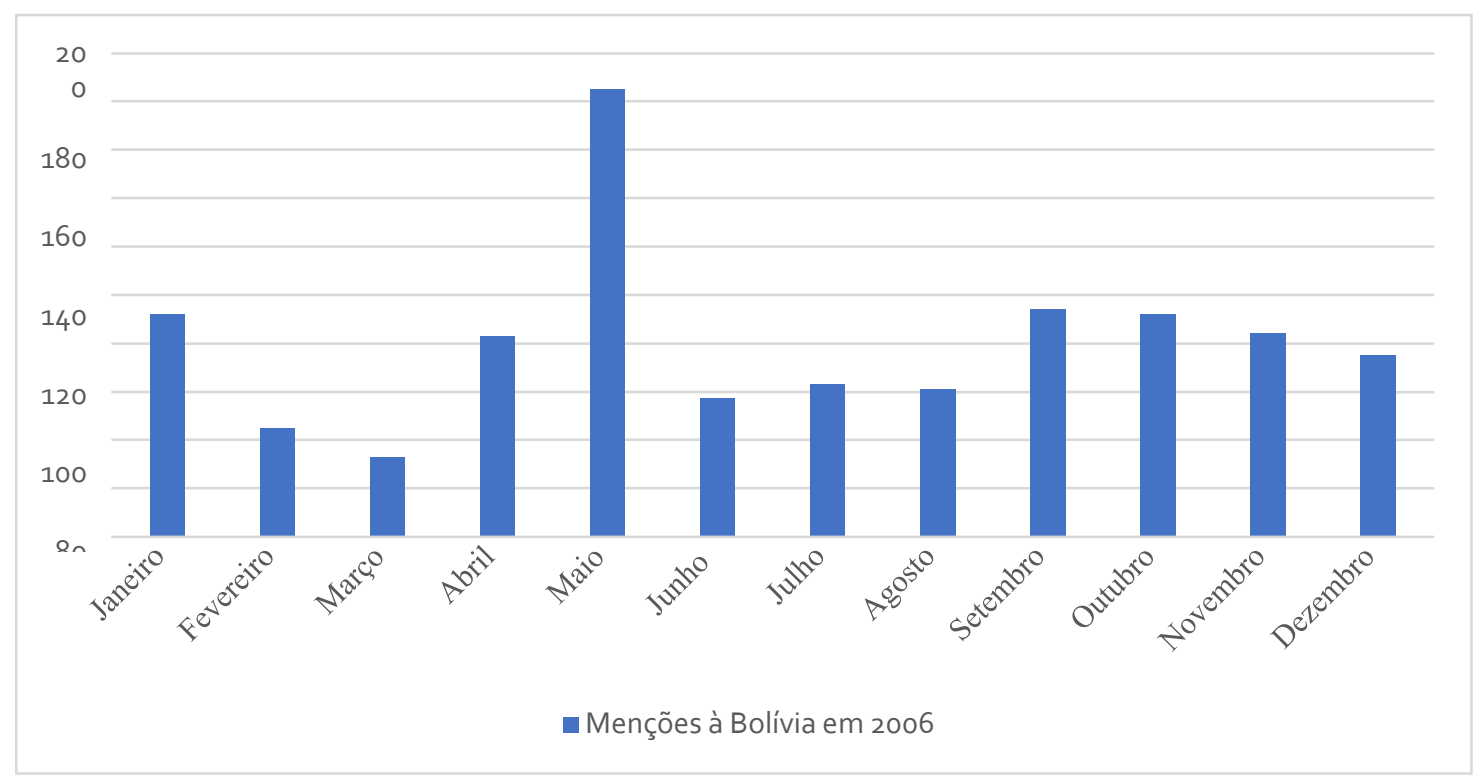

Fonte: Acervo Globo

Esse gráfico 01 demonstra o motivo da escolha de tratar as valências nos meses propostos inicialmente. O gráfico 02 demonstra a combinação das valências coletadas para os quatro casos aqui propostos, com relação ao Executivo Federal. Nele é nítida a representação de crise iminente e negativa para os casos relativos à Bolívia em 2006 e em 2013. Contrariamente, os casos venezuelanos de 2002 e de 2016 são tratados com neutralidade ou com certa positividade acerca das ações do Executivo federal para com o país. Com a análise de conteúdo empregada, percebeu-se uma permissividade por parte do jornal e, além disso, muita tentativa de se encapsular a problemática na própria Venezuela, lembrando que ocorreram em períodos de Fernando Henrique e de Michel Temer. Enquanto que os casos bolivianos demonstraram uma forte correlação de crise, com elementos já mencionados na sessão anterior - especialmente com a relação entre os dois países - o caso venezuelano se manteve isolado; houve, também, uma mudança de rumo com relação à terminologia adotada pelo jornal, que será melhor discutida na sessão seguinte. 
Gráfico $02^{11}$

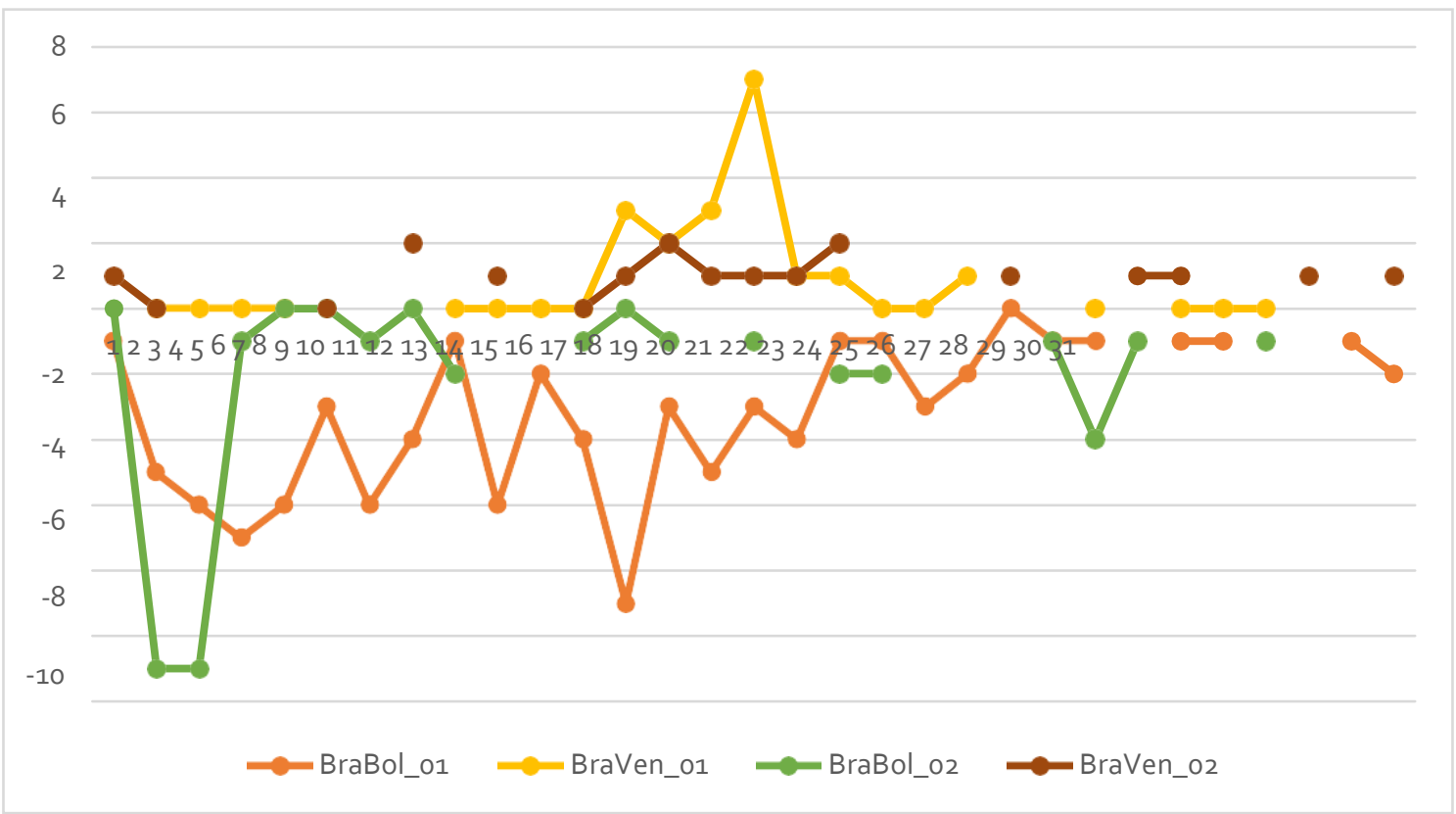

Fonte: $\mathrm{O}$ autor.

No caso da tentativa de golpe na Venezuela em 2002, o jornal manteve-se cauteloso com relação às posições adotadas pelo Brasil, mas deu como certa a queda de Hugo Chávez. A partir do momento em que Fernando Henrique (FHC) entende que Pedro Carmona, presidente empossado para o cargo de Hugo Chávez, não era legítimo na função de presidente e, concomitantemente, Chávez consegue se comunicar com maior ressonância, o Globo passa a seguir a ideia de FHC. O Globo entendeu, seguindo a análise feita, que Pedro Carmona não era legítimo e que a Venezuela merecia novas eleições. Portanto, houve adequação quanto à palavra relacionada ao golpe - antes não era entendido como tal -, mas com parcimônia com relação à Chávez. Não houve críticas alguma à atuação nem de FHC nem de Celso Lafer, por exemplo.

A nacionalização dos hidrocarbonetos bolivianos, em 2006, caiu como uma bomba para o jornal o Globo. O Executivo federal foi constantemente atacado pelos colunistas, pelas notícias, pelos editoriais e pelos convidados a se expressar. A pressão foi tanta que o chanceler Celso Amorim foi à audiência pública no Senado Federal e tanto Amorim quanto senadores utilizaram argumentos advindos da imprensa; era nítida a pressão

\footnotetext{
11 BraVen_01 representa 2002; BraBol_01 representa 2006; BraBol_02 representa 2013; BraVen_02 representa 2016.
} 
para imposição de agenda pública e, claramente, negativa. Não houve mudanças bruscas com relação à opinião inicial e final, mas houve uma enorme ansiedade movida pela noção de crise.

O senador Pinto Molina foi trazido para o Brasil, em 2013, após passar um longo período na embaixada brasileira em La Paz. Como ele não tinha salvo-conduto, Molina não poderia sair da embaixada e, além disso, possuía mandados de prisão em dois processos diferentes. O diplomata Eduardo Saboya o trouxe até o Brasil mesmo assim, o que foi reportado como ato de heroísmo do início ao fim. Curiosamente, Saboya foi tratado como herói, superando a lentidão da burocracia estatal, mas o chanceler Antônio Patriota e Dilma Rousseff foram tratados como inimigos. Foi invocado, a todo momento, a bravura de Saboya e a inimizade entre Rousseff e Patriota, que acabou pedindo demissão do cargo por conta disso.

A suspensão da Venezuela, em 2016, por conta da cláusula democrática do Mercosul foi movida após mudança de governo e de chancelaria. As notícias podem ser resumidas em: (i) diversas demonstrações de desespero socioeconômico na Venezuela e de falta de diálogo por parte do presidente venezuelano, que chegou a descartar conversas com Papa Francisco; (ii) Brasil como um ator diplomático seguro, democrático e em busca da melhor solução para a crise regional, que não pareceu ter tempo finito. Retratou- se, como no caso da tentativa de golpe em 2002, um encapsulamento da crise na delimitação da fronteira venezuelana e sem impactos maiores ao Brasil, que permaneceu diplomático.

A localização das notícias é representada pelas tabelas 01 e 02 que salientam onde esse debate ocorreu. Nota-se que a Tabela 1 - o caso boliviano de 2006 - representa uma concentração nas páginas de Economia $^{12}$ e nas de Opinião ${ }^{13}$; enquanto que o segundo caso boliviano mostra-se mais nas páginas País e Mundo, que são as páginas

\footnotetext{
${ }^{12}$ As páginas de economia, nos jornais brasileiros, têm peso hegemônico desde a década de 70, segundo Donadone (2000). Segundo o mesmo autor (ibidem, p.3): “O estudo realizado por Quintão, sobre o crescimento do noticiário econômico nas primeiras páginas dos jornais brasileiros, constatava que as manchetes de economia passavam, no jornal 'O Estado de São Paulo', de 1,4\% em 1969 para 21,3\% em 1978. No caso do 'Jornal do Brasil', o aumento era de 0,3\% em 1967 para chegar a 27,4\% em 1979".

${ }^{13}$ A página de Opinião é o locus em que os editores se expressam de maneira mais livre e direta com o leitor. Além disso, "os artigos de opinião têm uma relação estreita com a agenda de media, funcionando como um espaço de comentário da [atualidade]" (Figueiras, 2007, p. 2094)
} 
com conteúdos já direcionados a temas correlatos $^{14}$. Há, na segunda tabela, mais ênfase nas páginas de Economia e na Mundo, o que caracteriza uma escolha para manter o assunto da Venezuela localizada em assuntos mundiais e não relacionais com o Brasil; tendência que se segue no segundo caso venezuelano.

Tabela 1

Páginas BraBol_01 BraBol_02

\begin{tabular}{|c|c|c|}
\hline Economia & 52 & 3 \\
\hline O Mundo & 7 & 9 \\
\hline Opinião & 24 & 6 \\
\hline País & 3 & 26 \\
\hline Primeira Página & 15 & 4 \\
\hline Segunda Página & 10 & 5 \\
\hline Total Geral & 111 & 52 \\
\hline
\end{tabular}

Fonte: O autor.

Tabela 2

Páginas BraVen_01 BraVen_02

\begin{tabular}{|c|c|c|}
\hline Economia & 18 & 5 \\
\hline O Mundo & 24 & 12 \\
\hline Opinião & 7 & 3 \\
\hline País & 3 & 3 \\
\hline Primeira Página & 10 & 2 \\
\hline Segunda Página & 4 & 0 \\
\hline Total Geral & 66 & 25 \\
\hline
\end{tabular}

Fonte: $\mathrm{O}$ autor.

Pode-se inferir do gráfico 02 e das tabelas 01 e 02 que existiu vontade e uma movimentação do jornal o Globo para influenciar em temas que, ainda que

\footnotetext{
${ }^{14}$ Vejo duas hipóteses para isso: (i) houve a prisão de 12 torcedores do Corinthians por terem assassinado um torcedor boliviano e, portanto, o tema poderia estar absorvendo muito espaço no jornal; (ii) não havia espaço para se falar de economia com relação a esse tema e não havia tanta vontade de se mobilizar para esse tema em artigos de opinião
} 
semelhantes, foram tratados de maneira diferente. Nos momentos em que FHC e Temer estiveram a frente de temas relacionados à Venezuela, que é constantemente trazida pelo jornal o Globo, a percepção sobre a crise não foi a de emergência e de tempo finito para que se fosse tratado. Além disso, a valência demonstrou que houve aquiescência quanto às ações brasileiras acerca de uma crise. Contrariamente, nos momentos em que Lula e Dilma estiveram à frente dos temas bolivianos - que são trazidos de maneira secundária e à cabo de notícias que envolvam Chávez ou Maduro o Globo deu muita ênfase a emergência com que se deveria responder à crise. A valência foi totalmente negativa no tempo escolhido, ainda que com diferenças de localização no jornal entre os dois casos.

ii.

Analisando De Forma Crítica

É importante que se tenha em mente as motivações que levam às disparidades gritantes nas coberturas jornalísticas. A intenção não é, como fora mencionado, apenas salientar por meio de análise de conteúdo e apresentação de gráficos, mas também a de demonstrar o embate entre frações de classe nesses momentos de crise. É notório saber que a imprensa trata governos de maneiras diferentes e que há enquadramentos diversos, dependendo da posição e do país do jornal analisado. No caso deste artigo, o jornal o Globo faz parte do sistema midiático brasileiro, onde há uma inclinação conservadora facilmente perceptível e que, ao longo dos anos, tratou de adquirir feições mercadológicas liberais com a evolução do capitalismo.

Para analisar essas diferenciações, atentar-me-ei ao Nicos Poulantzas (1978; 1980) e a interpretação feita por Tatiana Berringer (2015) para mostrar as brigas de frações de classe em FHC e Lula - estendendo-me aos governos Dilma e Temer. No que se refere à política externa brasileira, vale sustentar uma visão de Estado que se baseia em Nicos Poulantzas (1978; 1980). Não caberá, infelizmente, um largo debate acerca de suas ideias, mas, no que se referir às noções de burguesias e frações hegemônicas, é interessante que sejam discutadas. Poulantzas (1980, p. 30) argumenta que não se pode entender o Estado sem compreender as relações de produção que esse constitui com as classes sociais e a própria luta de classes. Como já foi mencionado aqui, os grandes meios de comunicação têm relações estreitas com o os governos tanto de 
situação quanto de oposição a depender do caso. Poulantzas (1978) trabalha com frações de classes e suas disputas para impor agendas que dizem respeito à própria luta de classes tanto dentro da fração específica quanto fora. A exemplo de Poulantzas (1978, p. 70-84), quando trata do Estado-nação, ele denota três tipos de burguesias que são características do Estado capitalista: burguesia nacional, burguesia compradora e burguesia interna. A burguesia nacional é uma fração de classe que possui base de acumulação em seu país e, a depender da situação, pode se juntar para combater pautas imperialistas. A burguesia compradora é, contrariamente à anterior, de base de acumulação capitalista externa ao país em questão e pode se portar como agente do capital imperialista. A burguesia interna estaria entre as duas burguesias anteriores, já que possui características relativamente parecidas com as demais; define-se, portanto, por ter relações com o capital internacional, mas, ao mesmo tempo, possui base de acumulação interna o que a leva a não romper ligações com pautas que podem ser da burguesia nacional.

Dessa forma, acredito que haja uma relação histórica entre as pautas defendidas ou atacadas para a política externa brasileira a partir dos meios de comunicação a depender da fração hegemônica no bloco no poder. Como Berringer (2015) trabalha em livro baseado em sua tese de doutorado, as relações entre o Estado e as frações burguesas no poder explicam a mudança na atuação externa e internacional do Brasil. Quando Berringer (2015) analisa as mudanças entre a subordinação passiva dos tempos de Fernando Henrique Cardoso e os tempos de subordinação conflitiva, durante o período Lula da Silva, é perceptível que a mudança das frações burguesas primeiramente a fração hegemônica era a burguesia compradora, já que foi ligada ao capital financeiro nacional e internacional, e deu lugar à grande burguesia interna - foi objeto de disputa de classes. Essa disputa pôde ser percebida nas desqualificações tratadas pelo jornal o Globo, que, ao meu entender, se enquadram na burguesia interna, mas que se aproxima, cada vez mais, da burguesia compradora pela própria lógica de mercado que a empresa tomou ao longo dos anos. No caso da Bolívia, foi evidente que houve enquadramentos com o intuito de desqualificar não só o governo e o Partido dos Trabalhadores, mas também a fração politicamente hegemônica no bloco no poder. A 
partir desse caso específico, pode-se depreender que a luta de classes nos demonstra a luta de poder latente dentro do Estado e do espaço que os grandes meios de comunicação pretendem adquirir.

Parte-se, portanto, de uma visão totalizante de Estado, que é responsável pelas suas políticas sejam elas internas ou externas. Partindo da evolução histórica interna dos meios de comunicação e sua relação direta com o Estado, além do nosso modelo de democracia representativa ser muito ligado por alianças e coalizões ${ }^{15}$ em torno de figuras poderosas, o modo pelo qual o jornal age ou reage à determinadas decisões externas diz respeito à posição que uma fração burguesa toma em frente à dominante. Essas características nacionais são essenciais para que se interprete, da maneira proposta a esta dissertação, temas de política externa.

É, portanto, imprescindível a este artigo que se pense em política externa nesses moldes apresentados. Com relação aos governos FHC e Temer, há uma clara convergência de interesses do jornal o Globo, representando boa parte dos grandes meios de comunicação tradicionais, e sendo perceptível no gráfico 02 e nas tabelas 01 e 02. Contrariamente, os governos Lula e Dilma foram enquadrados totalmente divergentes aos interesses do jornal o Globo, algo que foi, também, perceptível a partir da análise de conteúdo. As frações burguesas no bloco no poder, durante FHC e Temer, tiveram características de burguesia compradora - priorizando pautas neoliberais; de forma inversa, as frações burguesas no bloco no poder, em Lula e Dilma, eram mais voltadas à burguesia interna. Importante notar que não houve momentos em que a burguesia nacional estivesse na fração hegemônica, ainda que se tenha enquadrado dessa maneira pelos grandes meios de comunicação.

\section{NOVAS AGENDAS CRÍTICAS}

A intenção deste artigo não é o de desmerecer ou de retirar o mérito de qualquer outro trabalho que analise política externa brasileira sem considerar o papel político da mídia. Há, claramente, correntes majoritárias nos estudos de política externa no Brasil e, com muito mérito, conformaram-se em ótimas análises interpretativas. No entanto, constatou- se não só por mim, mas também por Armando Boito Jr., ao escrever o

\footnotetext{
${ }^{15}$ Abranches (1988).
} 
prefácio de Berringer (2015), e por MacMillan (2004), em sua dissertação, que há poucos pesquisadores de Relações Internacionais utilizando abordagens críticas ou marxistas. No caso de Berringer (2015), percebeu-se que não se utilizam ferramentais marxistas ou neomarxistas para se analisar política externa no Brasil. No caso de MacMillan (2004), não há utilização corrente de Teoria Crítica para as mídias nas Relações Internacionais, especialmente de forma sistemática. Com base nessas duas reflexões que este artigo surgiu.

Entre as possibilidades de novas agendas, julgo necessárias duas abordagens que conversam entre si e que podem ajudar no desenvolvimento da área de Relações Internacionais no Brasil. Com base nas constatações desse artigo, uma agenda de pesquisa a ser mais difundida deveria ser a de base marxista ou neomarxista em análises de política externa, que agreguem visões de Estado diferentes das já muito utilizadas não só no Brasil, mas também no exterior ocidental - os realismos, os liberalismos, o construtivismo e os pós-colonialismo e pós-estrturalismo. Lembrando que a Teoria Crítica conversa bem com autores (neo)marxistas, uma outra agenda de pesquisa poderia ser a de se desenvolver, teoricamente, o papel das mídias nas Relações Internacionais com base em autores críticos. Ambas as agendas estão sendo discutidas em minha dissertação e em alguns trabalhos apresentados em congressos, mas há, ainda, pouca unificação em torno de uma ou das duas agendas no Brasil.

Para finalizar este artigo, cito Axel Honneth (2008), que escreveu sobre o legado da Teoria Crítica para as Ciências Sociais e a preocupação central de todo autor que utilize essa teoria

Por mais fortemente influenciados por Marx que possam ser em suas peculiaridades, quase todas as abordagens da Teoria Crítica compartilham uma premissa operativa central em sua análise do capitalismo, concernente a esse ponto singular: as circunstâncias sociais que constituem a patologia das sociedades capitalistas têm a característica estrutural peculiar de encobrirem precisamente aquelas circunstâncias que deveriam de outro modo prover de maneira particular os fundamentos indispensáveis para a crítica pública. [...] Em contraste com as abordagens que atualmente têm alcançado predominância, a Teoria Crítica deve associar a crítica da injustiça social com uma explicação dos processos que obscurecem tal injustiça. (Honneth, 2008, p. 401). 


\section{REFERÊNCIAS BIBLIOGRÁFICAS}

Abranches, S. (1988). 'Presidencialismo de coalizão: o dilema institucional brasileiro', Dados - Revista Brasileira de Ciências Sociais. Rio de Janeiro: IUEPERJ, Vol.1.

Adorno, T; Horkheimer, M. (2012). Dialética do Esclarecimento. Rio de Janeiro: Zahar. . (2009). Dialética Negativa. Rio de Janeiro: Zahar.

Aldé, A.; Mendes, G.; Figueiredo, M. (2007). 'Tomando partido: imprensa e eleições presidenciais em 2006', Política \& Sociedade, [s.I.], 6(10), p.153-172. Disponível em: $<$ https://periodicos.ufsc.br/index.php/politica/article/view/1688>. [Acesso em: 22 out. 2018].

Aristóteles. (1967). Obras. Juan Bravo: Aguilar, p. 1634. Tradução de Francisco P. Samaranch.

Berringer, T. (2015). A burguesia brasileira e a política externa nos governos FHC e Lula. Curitiba: Appris, p. 237.

Brunkhorst, H. (2008). 'A teoria crítica e a análise da sociedade contemporânea de massa'. In: Rush, Fred (Org.). Teoria Crítica. São Paulo: Ideias \& Letras, p. 295-328. Tradução de Beatriz Katinsky e Regina Andrés Rebollo.

Butler, J. (1997). The Psychic Life of Power: Theories in Subjection. Stanford: Stanford University Press, p. 118.

Camargo, J. (2012). Mídia e Relações Internacionais: lições da invasão do Iraque em 2003. Curitiba: Juruá, p. 152.

Casarões, G. (2012). 'A Mídia E A Política Externa No Brasil De Lula', Austral: Revista Brasileira de Estratégia e Relações Internacionais, Porto Alegre, 1(2), p.211-236. Semestral. Disponível em: <http://seer.ufrgs.br/index.php/austral/article/viewFile/32661/20524>. [Acesso em: 29 ago. 2019].

Deibert, R. J. (1997). Parchment, Printing, and Hypermedia: Communications in World Order Transformations. Nova Iorque: Columbia University Press.

Donadone, J. (2000). Imprensa de negócios, dinâmica social e os gurus gerenciais. Encontro Da Associação Nacional De Pós-Graduação E Pesquisa Em Administração (EnANPAD). Disponível em: <http://www.anpad.org.br/admin/pdf/eneo2000-16.pdf>. [Acesso em: 1 fev. 2019].

Faria, C. (2008). 'Opinião pública e política externa: insulamento, politização e reforma na produção da política exterior do Brasil', Revista Brasileira de Política Internacional, Brasília, 51(2), p. 80-97. Disponível em: <http://www.scielo.br/scielo.php?script=sci_arttext\&pid=S0034- 
73292008000200006\&lng=en\&nrm=iso>. [Acesso em 29 ago. 2019]. http://dx.doi.org/10.1590/S0034-73292008000200006.

Feres Junior, J. (2016). 'Análise de valências, debate acadêmico e contenda política', Revista Brasileira de Ciência Política, Brasília, n. 20, p. 313-322. Disponível em: $<$ http://www.scielo.br/scielo.php?script=sci_arttext\&pid=S0103-

33522016000200313\&lng=en\&nrm=iso>. [Acesso em 31 jan. 2019]. http://dx.doi.org/10.1590/0103-335220162009.

Figueiras, R. (2007). 'O Comentário Político e a Política do Comentário', Comunicação e Cidadania: Actas do 50 Congresso da Associação Portuguesa de Ciências da Comunicação, Braga, 1(1), p. 2093-2106. Disponível em: <http://revistacomsoc.pt/index.php/5sopcom/article/viewFile/185/181>. [Acesso em: 1 fev. 2019].

França, Vera et al. (2018). 'Comunicação e Política: um mapeamento de autores/as e teorias que alicerçam essa área no Brasil', Revista Compolítica, [s.l.], 8(2), p. 5-40. Disponível em: <http://compolitica.org/revista/index.php/revista/article/view/183>. [Acesso em: 29 ago. 2019]. http://dx.doi.org/10.21878/compolitica.2018.8.2.183

Frederico, C. (2007). 'Brecht e a "Teoria do rádio"', Estudos Avançados, São Paulo, 21(60), p. 217-226. Disponível em $<$ http://www.scielo.br/scielo.php?script=sci_arttext\&pid=S010340142007000200017\&lng=en\&nrm=iso>. [Acesso em 29 de agosto de 2019]. http://dx.doi.org/10.1590/s0103-40142007000200017.

Gilboa, E. (1987). American public opinion toward Israel and Arab-Israeli conflict. Lexington: Lexington Books.

. (2001). 'Diplomacy in the media age: Three models of uses and effects',

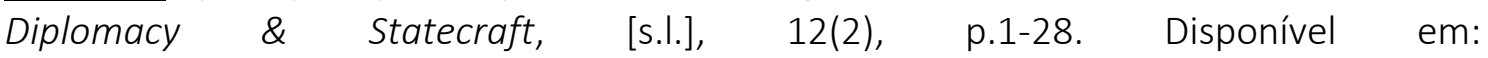
<https://www.tandfonline.com/doi/abs/10.1080/09592290108406201>. [Acesso em: 09 jun. 2019]. http://dx.doi.org/10.1080/09592290108406201.

Habermas, J. (1988). Legitimation Crisis. Cambridge: Polity Press, p. 190. Tradução de Thomas McCarthy.

Held, D.; McGrew, A. (2001). Prós e Contras da Globalização. Rio de Janeiro: Zahar.

Honneth, A. (2008). 'Uma patologia social da razão: sobre o legado intelectual da Teoria Crítica'. In: Rush, Fred (Org.). Teoria Crítica. Aparecida: Ideias \& Letras, p. 389-415. Tradução Beatriz Katinsky, Regina Andrés Rebollo.

Lattman-Weltman, F. (1994). A imprensa faz e desfaz um Presidente: o papel da imprensa na ascensão e queda do "fenômeno" Collor. Rio de Janeiro: Nova Fronteira, p. 166. 
Lessa, M.; Gavião, L. (2010). 'Política externa, mídia e propaganda nos governos Lula da Silva (2003-2010)'. In: Freixo, Adriano de et al (Org.). A Política Externa Brasileira na era Lula: Um balanço. Rio de Janeiro: Apicuri, p. 106-151.

Lima, V. (2004). Mídia: Teoria e Política. Belo Horizonte: Fundação Perseu Abramo, p. 368.

Linklater, A. (1992). 'The Question of the Next Stage in International Relations Theory: A Critical-Theoretical Point of View', Millennium: Journal of International Studies, [s.I.], 21(1), p.77-98. SAGE Publications. Disponível em: <https://journals.sagepub.com/doi/10.1177/03058298920210010601>. [Acesso em: 25 ago. 2019]. http://dx.doi.org/10.1177/03058298920210010601.

Macmillan, A. (2004). Toward a Critical Theory of the Media in International Relations. 51 f. Dissertação de Mestrado, Curso de Ciência Política, Departamento de Ciência Política, Simon Fraser University, Burnaby.

Martino, L. (2015). 'De qual comunicação estamos falando?' In: Hohlfeldt, A.; Martino, L. C.; França, V. V. (Org.). Teorias da comunicação: conceitos, escolas e tendências. 15. ed. Petrópolis: Vozes, Cap. 1, p. 11-26.

Medeiros, F.; Ramalho, M.; Massarani, L. (2010). 'A ciência na primeira página: análise das capas de três jornais brasileiros', História, Ciências, Saúde - Manguinhos, Rio de Janeiro, 17(2), p. 439-454. Disponível em: < https://www.arca.fiocruz.br/bitstream/icict/23929/2/pdf\%2013.pdf>. [Acesso em: 20 out. 2018].

Miguel, L. (1999). 'Mídia e eleições: a campanha de 1998 na Rede Globo', Dados, Rio de $\begin{array}{lll}\text { Janeiro, } & \text { 42(2). Disponível } \\ <\text { http://www scielo.br/scielo.php?script=sci arttext\&pid=S0011- }\end{array}$

52581999000200002\&Ing=en\&nrm=iso>. [Acesso em: 29 ago. 2019]. http://dx.doi.org/10.1590/s0011-52581999000200002.

(2004). 'A descoberta da política: a campanha de 2002 na Rede Globo'. In: Rubim, A. A. C. (org.). Eleições presidenciais de 2002 no Brasil: ensaios sobre mídia, cultura e política. São Paulo: Fundação Perseu Abramo.

(2015). Quanto vale uma valência? Revista Brasileira de Ciência Política,

[s.l.], n. 17, p.165-178. FapUNIFESP (SciELO). Disponível em: <http://dx.doi.org/10.1590/0103-335220151706>. [Acesso em: 31 jan. 2019].

. (2016). 'Uma resposta', Revista Brasileira de Ciência Política [s.l.],

FapUNIFESP (SciELO), n. 19, p.299-301. Disponível em: <http://www.scielo.br/pdf/rbcpol/n19/2178-4884-rbcpol-19-00299.pdf>. [Acesso em: 31 jan. 2019]. http://dx.doi.org/10.1590/0103-335220161912.

Monteiro, L. (2007). Política Externa na era da informação: O novo jogo do poder, as novas diplomacias e a mídia como instrumento de Estado nas Relações Internacionais. Rio de Janeiro: Revan, p. 192. 
Poulantzas, N. (1978). Classes in Contemporary Capitalism. Londres: NLB, p. 334.

. (1980). O Estado, o Poder e o Socialismo. Rio de Janeiro: Graal, p. 307. Tradução de Rita Lima.

Salomon, M.; Pinheiro, L. (2013). 'Análise de Política Externa e Política Externa Brasileira: trajetória, desafios e possibilidades de um campo de estudos', Revista Brasileira de Política Internacional, Brasília, 56(1), p. 40-59. Disponível em: $<$ http://www.scielo.br/scielo.php?script=sci_arttext\&pid=S0034-

73292013000100003\&lng=en\&nrm=iso>. [Acesso em 29 ago. 2019]. http://dx.doi.org/10.1590/S0034-73292013000100003.

Shapcott, R. (2008). 'Critical Theory'. In: Reus-Smit, Christian; Snidal, Duncan (Ed.). The Oxford Handbook of International Relations. Oxford: Oxford University Press, p. 327345. 